\title{
GAMIDEN: A Program to Aid in the Identification of Unknown Materials by Gamma-Ray Spectroscopy
}

\author{
R. J. Howerton
}

Manuscript Date: June 25, 1982

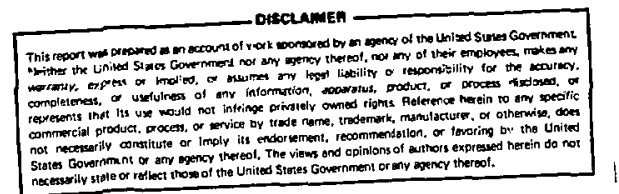

LAWRENCE LIVERMORE LABORATORY University of California $\bullet$ Livermore, California 94550 


\section{Fencmers}

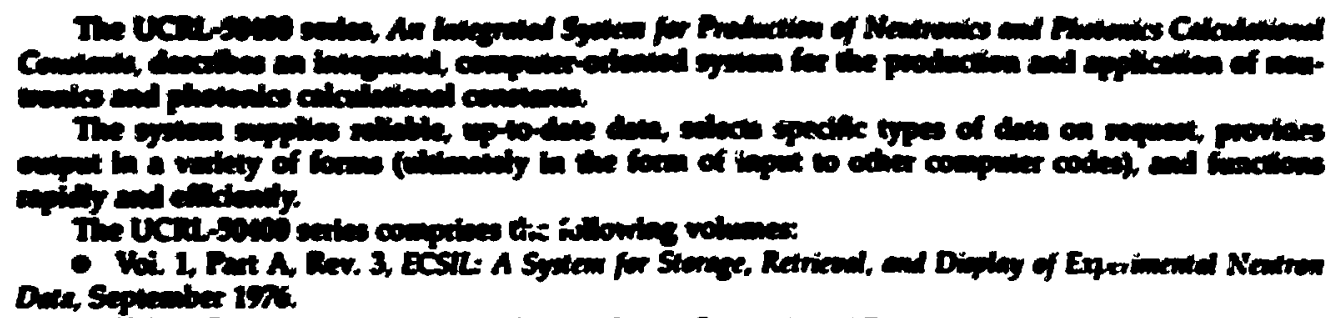

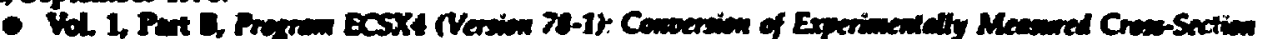

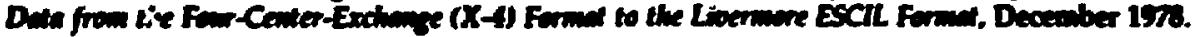

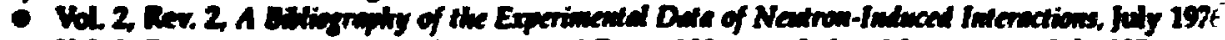

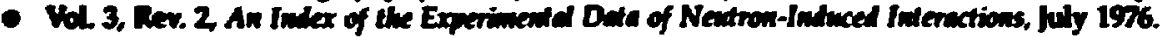

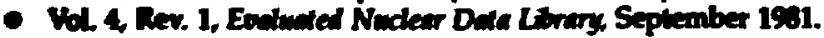

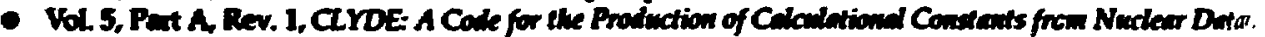
Seplember 1973.

- Vol. 5, Part B, Rev. 1, Relativistic Tranoformations between Cender-of-Mass and Laboratory Systims for Troo-Baily Nuclear Reactions, April 1976.

- Vol. 6, Rev. 2, Tdiles and Graphs of Photon-Interaction Cross Sections from 1 keV to 100 MeV. December 1978.

- Vol. 7. Part A, Rev. 1, Major Neutron-Induced Interactions ( $Z \leq 55)$ : Graphical, Experineented Data, July 1976.

- Vol. 7, Part B, Rev. 1, Major Neutron-Induced Interactions (Z > 55): Graphical, Experimental Date, July 1976.

- Vol. 8, Part A, Rev. 1, Supplemenlal Neutron-Induced Interactions ( $Z \leq 35)$ : Graplical, Experimental Data, July 1976.

- Vol. B, Part B, Rev. 1, Supplemental Neutron-Induced Interactions ( $Z>$ 35): Graphical, Experimental Dafa, July 1976.

- Vol. 9, Thresholds of Nuclear Reactions Induced by Neutrons, Photons, Deuterons, Tritons, and Alphe Particles, September 1970.

- Vol. 10, Rev. 1, Tabulated Experimental Data for Neutron-Induced Interaclions, July 1976.

- Vol. 11, Experimental Data, Indexes, and Techniques of Obtaining a Selected Set of Neutron Resanance Parameters, May 1972.

- Vol. 12, An Atlas of Resolved Neutron Resonance Parameters, July 1972.

- Vol. 13, An Atlas of Unresolved Neutron Resonance Parameters, September 1972.

- Vol. 14, TARTNP: A Coupled Neutron-Photon Monte Carlotransport Code, February 1976.

- Vol. 15, Part A, The LLL Evaluated-Nuclear-Data Library (ENDL): Evaluation Techniques, Reaction Index, and Descriptions of Individual Evaluations, September 1975.

- Vol. 15, Part B, Rev. 1, The LLL Evaluated-Nuclear-Data Library (ENDL): Graphs of Cross Sections from the Library, October 1978.

- Vol. 15, Part C, The LLL Evaluated-Nuclear-Data Library (ENDL): Translation of ENDL NeutronInduced Interaction Data into the ENDF/B Format, April 1976.

- Vol. 15, Part D, Rev. 1, The LLL Evaluated-Nuclear-Data Library (ENDL): Descriptions of Individual Evaluations for $Z=0-98$, May 1978.

- Vol. 15, Part E, Data Testing Results for the LLL Nuclear Data Library (ENDL-78), August 1979.

- Vol. 15, Part F, Experimental and Evaluated Elastic Nuclear Plus Interference Cross Sections for Light Charged Particles, July 1980.

- Vol. 16, Rev. 2, Tabular and Graphical Fresentation of 175 Neutron-Group Constants Derived frnm the LLL Evaluated-Nuclear-Data Library (ENDL), October 1978.

- Vol. 17, Part A, Rev. 2, Program LINEAR (Version 79-1): Linearize Data in the Evaluated-Nuclear-Data File/Version B (ENDF/B) Format, October 1979.

- Vol. 17, Part B, Rev. 2, Program SIGMA1 (Version 79-1): Doppler Broaden Evaluated Cross Sections in the Evaluated-Nuclear-Data File/Version B (ENDF/B) Format, October 1979. 


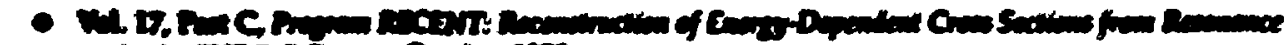

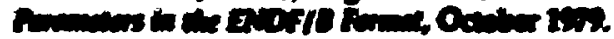

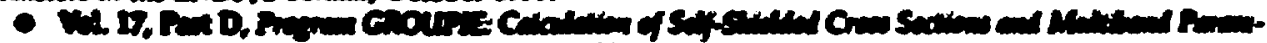

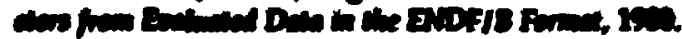

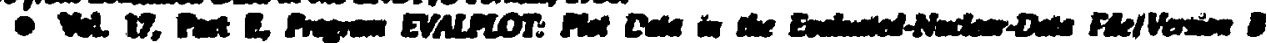

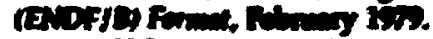
19.

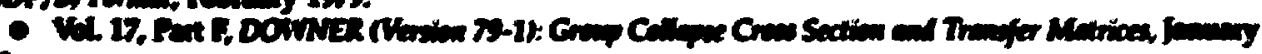

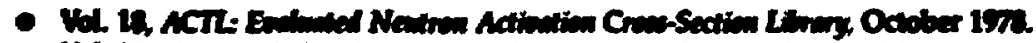

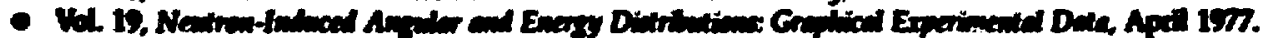

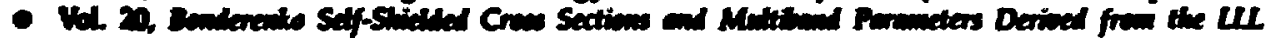

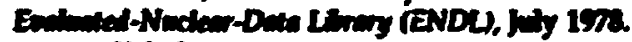

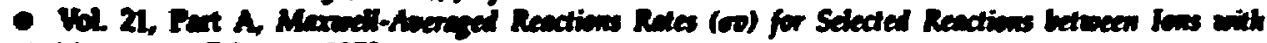
Alomic Mas $\leq 11$, Fedowery 1579.

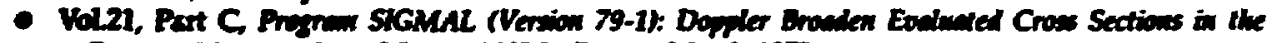

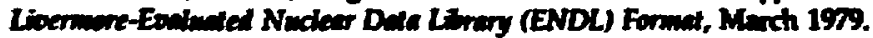

- Vol. 22, Rev. 1, GAMDEN: A Program to Ail in the Identification of Undrown Materials by GavanaRigy Spectroscopy, June 1902.

- Vol. 23, ENSL an CDRL. Evaluated Nuclear Stnucture Liraries, February 1981.

- Vol. 24. Thresholds and $Q$ Values of Nuclear Reactions Induced by Newtrons, Protons, Deaterons, Tritons, 'He lons, Alphe Particles, and Photons, March 1981. 


\title{
GAMIIDEN: A Program to Aid in the Identification of Unknown Materials by Gamma-Ray Spectroscopy
}

\begin{abstract}
Abatract
The intent of the computer code GAMIDEN is to help identify sotopes by their gamma-ray emiscions and thus to ascist in the nondestructive sasay of unknown materials. From both radionctive decays and neutron coptures, GAMIDEN searches GAMTOT78, a file of gamma-ray spectra, for matches with observed photon energies. This report describes the search procedure, outlines the use of the code, and gives an example.

The code is designed to operate on the CRAY 1 computer at Lawrence Livermore National Laboratory (LLNL). It is written in standard Fortran (ANSI) for the most part but contains some LRLTRAN instructions to make use of the Livermore time-sharing system (LTSS). The code uses about 545,000 words of memory. Typical problems run in about $45 \mathrm{~s}$. The source program and the data file are available on request.
\end{abstract}

\section{Introduction}

The gamma rays emitted by an isotope undergoing radioactive decay or neutron capture have energies and intensities that are characteristic of that isotope. Such a set of gamma rays is often referred to as the signature of the isotope. A useful method for the nondestructive assay of unknown materials is based on identifying the signature of the isotope.

Since there are thousands of known gamma rays, we have developed an automated search procedure. GAMIDEN, a computer code, searches GAMTOT78, a disk file of gamma-ray spectra, for isotopes that match observed gamma energies. GAMIDEN lists the matching isotopes, eliminates isotopes that are not likely to be the source of the observed photons, and then lists the isotopes that are left-the likely candidates. The user makes any further analysis required to identify the actual source isotopes.

\section{Search Procedure Used in GAMIDEN}

The search procedure used in GAMIDEN is outlined as follows:

1. Given a set of observed photon energies, search the tabulated data for photons with the same energies, within experimental uncertainty. Isotopes that emit such photons form the initial list of possible sources of the observed photons.

2. Examine the tabulated spectrum of each isotope for gammas that have a higher probability of emission than the observed gamma has; presumably, such gammas should have been observed as well.

3. Examine energies of the other observed photons to see if these higher-probability gammas, if any, were, in fact, observed.

4. If the matching isotope's spectrum contains a higher-probability gamma and it was not observed, remove this isotope from the list of possible sources. Isotopes that survive this test constitute the final list of possible sources. 


\section{Inoling the Samch}

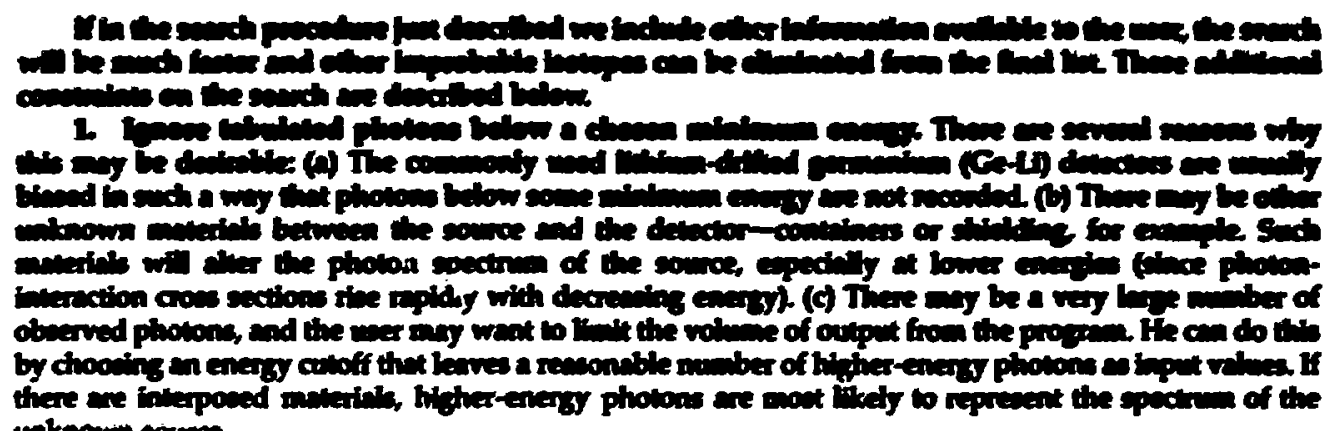

unknowin source.

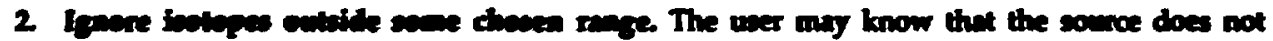
contain isotopes outside some range of atomic mumber $Z$ and mas manber $A$, or he my sioply be uninterested in isotopes outside of some such range. The user combines the $\mathbf{Z}$ and $A$ of these tiniting isotopes into numbers equal to $1000 Z+A$, and enters these to indicate the limits chomen.

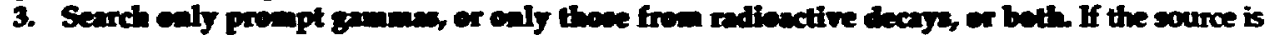
not emitting prompt gammas or gammas from decays with very short half-lives, the uver can specify a minimum half-life as a criterion for searching. He can set this value to zero if he wants to search both prompt and decay gammas. (In GAMTOT78 prompt gammas are assigned a half-life of $10^{-11} \mathrm{~s}$.)

(Of course, the capture process may result in the formation of a radioactive product, which will decay with its own characteristic spectrum and half-life. The user may need to consider this in dzciding whether to search prompt gammas only.)

4. Do not consider gammas with a low probability of emission. Clearly low-probability photons, even if present in the unknown spectrum, may not be detected. (The tabulated probabilities, also called multiplicities, are actually probabilities of emission per decay or per neutron capture.)

The user will also have to estimate the uncertainty to be associated with each observed photon energy. The Ge-Li detector has an accuracy of plus or minus a few keV for photon energies in the range from $100 \mathrm{keV}$ to $10 \mathrm{MeV}$. This uncertainty arises mainly from the nonlinearity of the relationship between photon energy and detector output. (A Ge-Li detector operated at liquid-nitrogen temperature has a precision of about $0.1 \mathrm{keV}$ for photons in this energy range.) Unknown energies are determined by interpolating or extrapolating detector output values from known photons; typically, only a few such calibration photons are used. To take account of asymmetry in the calibration, the program permits the user to specify different values for the uncertainties above and below the observed energies.

\section{Program Output}

GAMIDEN provides four kinds of output information:

1. The input data (search constraints and photon energies).

2. A list of each match of an observed photon giving the identity of the matching isotope and a list of all the photons in the spectrum of the matching isotope that satisfy the search constraints.

3. A list of the isotopes that have no unobserved higher-probability photons. These isotopes remain active candidates.

4. A list of the eliminated isotopes, with the multiplicity and energy of both the observed and the unobserved higher-multiplicity photon. 


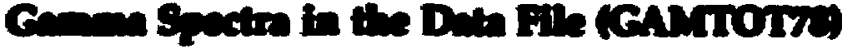

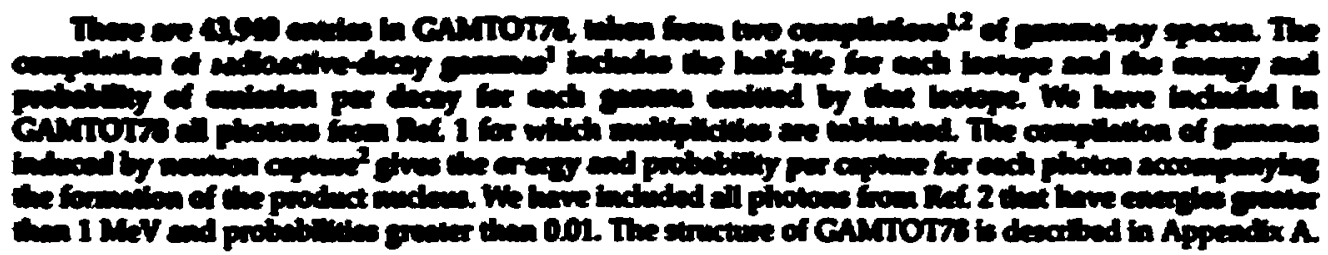

\section{Uaing GAMIDEN}

UNL

This section deals with the we of GAMIDEN per se; Appendix B details the we of GAMIDEN a

Moat likely the user will want to enter the search constraints from his console so that he can alker them after seeing the program output. However, if there are many observed photon erengies, he may want to enter photon energies from a user-created disk file. GAMIDEN allows the user to enter his data from a console or from a disk file. The disk file contains the observed photon energies in format 10 F7.3. The last record of the data file should be blank. The program will request the name of the disk file, which must be less than or equal to eight characters.

The program prompts the user as follows:

\section{ENTER NAME OF SOURCE FILE IN A8, E.G., GAMTOT79}

This gives the user the option of using a data file other than GAMTOT78 if he wishes to do so. Of course, any other data file must be in the same format as GAMTOT78. (See Appendix A for a description of the required format.)

\section{ENTER DETECTOR SHIFTS LOWER, THEN UPPER IN 2 F7.3}

Note that these uncertainties, although of the order of a few keV, are entered in MeV. The user may use either a 2 F7.3 format or a field-free, floating-point format and delimit the two variables with a comma.

\section{ENTER LOWER ENERGY LIMIT FOR GAMMAS IN F7.3}

This suppresses the search for energies less than the entered value. The unit of energy is $\mathrm{MeV}$.

ENTER LOWER AND UPPER LIMITS OF ISOTOPES IN 216

These two numbers, entered as $1000 \mathrm{Z}+\mathrm{A}$, limit the range of isotopes searched.

ENTER LOWER BOUND of HALF-LIFE IN SEC. (F10.3)

This suppresses the search for unreasonably short half-lives. Enter zero if all isotopes are to be searched. IF CAPTURE GAMMAS ONLY ENTER YES; OTHERWISE LF

A "YES" causes the program to ignore the previous entry and search only for gammas from Ref. 2 associated with neutron capture.

ENTER INPUT DEVICE FOR OBSERVED GAMMAS: 06 IF FILE; 59 IF TTY 


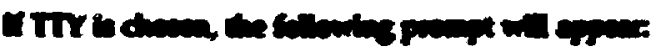

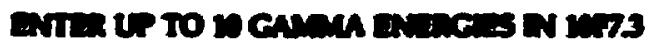

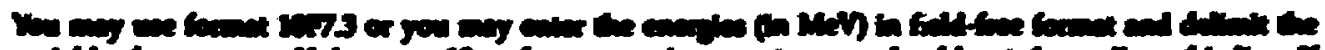

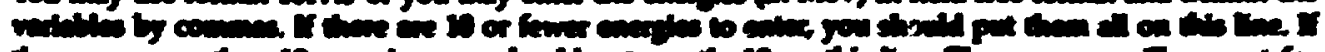

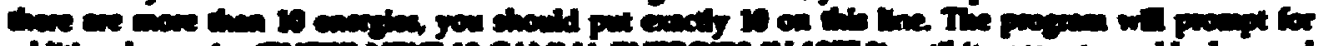

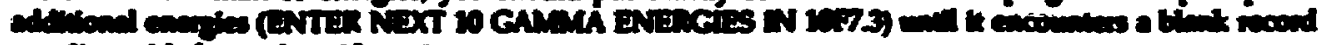

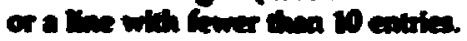

ENTER LOWER COUND OF MULTPLCTIES IN F7.3

This suppereses the seanch for low-probability phovens.

After output is conpleted the user is prompted for further problems:

IF ANOTHER PROALM ENTER 1; IF NOT LF

The program will request another set of observed photon energies.

\section{Example Input}

- Assume that observed photon energies are $0.058,0.826,1.173,1.332$, and $2.158 \mathrm{MeV}$.

- Consider all tabulated isotopes between ${ }_{20} \mathrm{Ca}^{40}$ and ${ }_{82} \mathrm{~Pb}^{207}$ with half-lives greater than $660 \mathrm{~s}$ (11 $\min$ ).

- Consider all tabulated photons with energies greater than $0.80 \mathrm{MeV}$ and probabilities greater than $10 \%$.

- Accept as a match any photon that satisfies the criteria above and is within plus or minus $0.005 \mathrm{MeV}$ $(5 \mathrm{keV})$ of an observed photon.

The user would enter these data from his console, as shown in the dialogue below.

ENTER NAME OF SOURCE FILE IN A8, E.G., GAMTOT78

GAMTOT78

ENTER DETECTOR SHIFTS LOWER THEN UPPER IN 2F7.3

$\underline{.005, .005}$

ENTER LOWER ENERGY LIMIT FOR GAMMAS IN F7.3

.80

ENTER LOWER AND UPPER LIMITS OF ISOTOPES IN $\mathbf{2 i 6}$

2004082207

ENTER LOWER BOUND OF HALF-LIFE IN SEC., (F10.3)

660.

IF CAPTURE GAMMAS ONLY ENTER YES; OTHERWISE LF

ENTER LOWER BOUND OF MULTIPLICITIES (F7.3)

II 
2

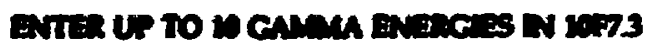

$\sin 1.176,132,215$

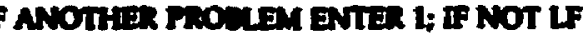

\section{Somple Outpat}

HOUT, a diak file of revits, is genarabed when GAMIDEN is mo. The reoults from the smole problem axe lined and expleined below.

1. The input variables are printed out (Fiz 1).

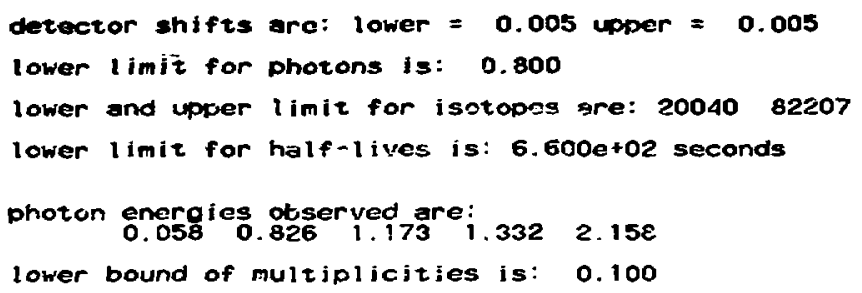

Figure 1.

2. The GAMTOT78 table is searched for isotopes that satisfy the input criteria. Each such isotope is printed out, accompanied by a list of other gamma emissions from the isotope that one might expect to see. The list below (Fig. 2), for the sample problem, gives the possible isotopes found in this way. The symbols used ir. the column labeled SOURCE are described in Appendix A.

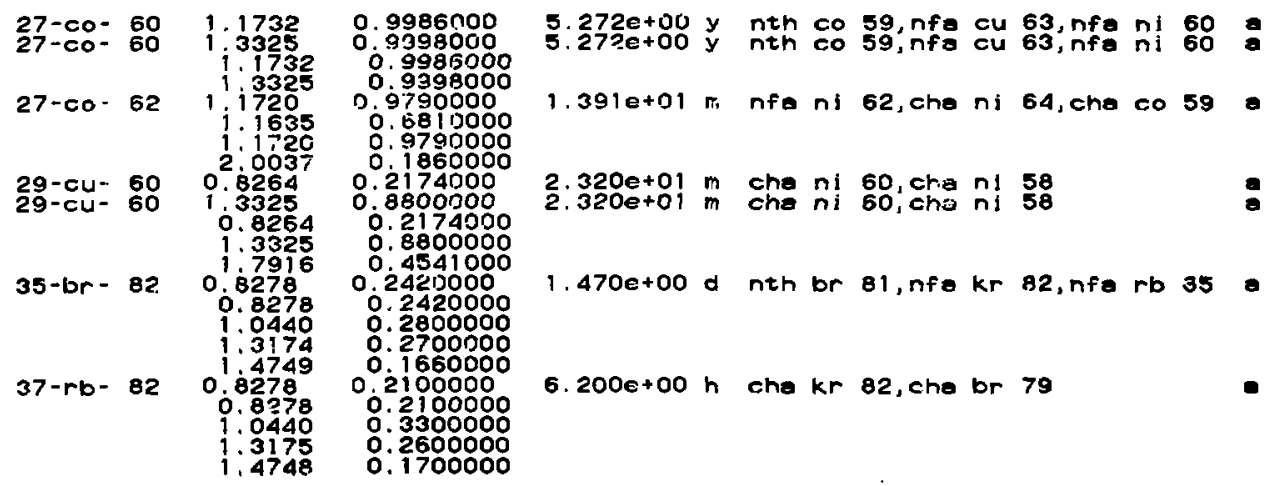

Figure 2. 


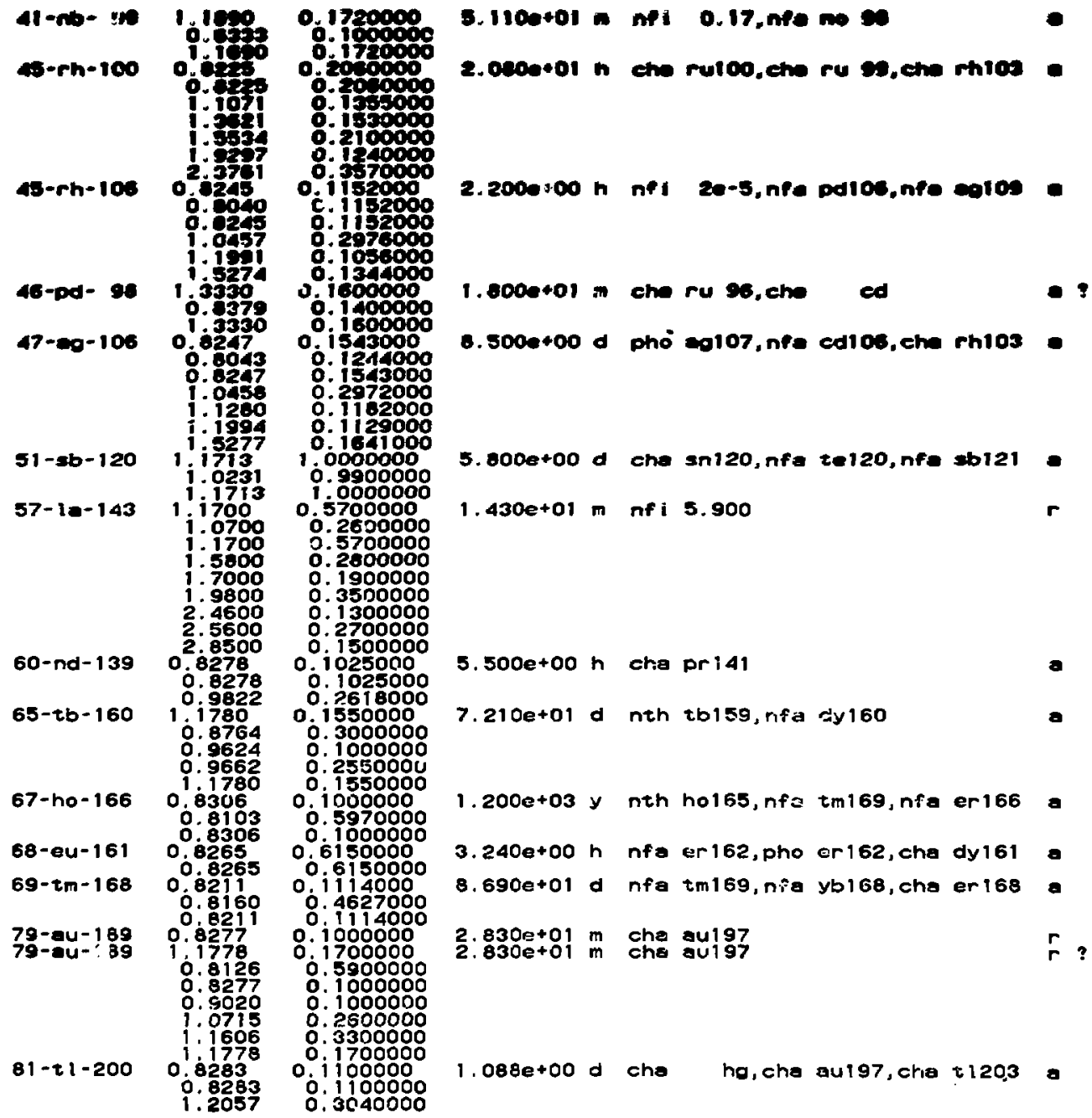

Figure. 2. (Continued)

3. The elimination criterion (no unobserved higher-multiplicity photon) is applied, and those isotopes that survive this test are listed (Fig. 3).

Of these candidates ${ }_{27} \mathrm{Co}^{60}$ is most probable since it has two gammas that meet the search criteria and both were observed. The other isotopes, for which only one of one or more possible gammas were observed, are less-probable candidates. 


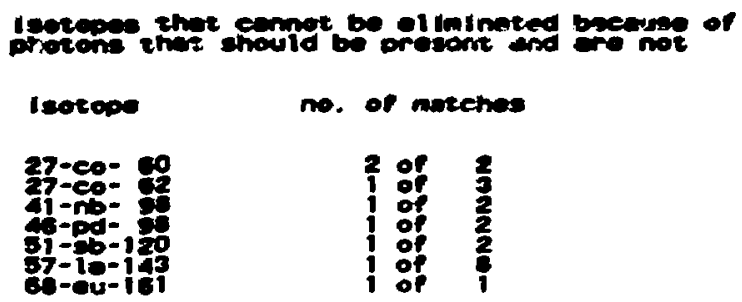

Figare 3.

4. The isotopes eliminated in the preceding step are listed (Fig. 4).

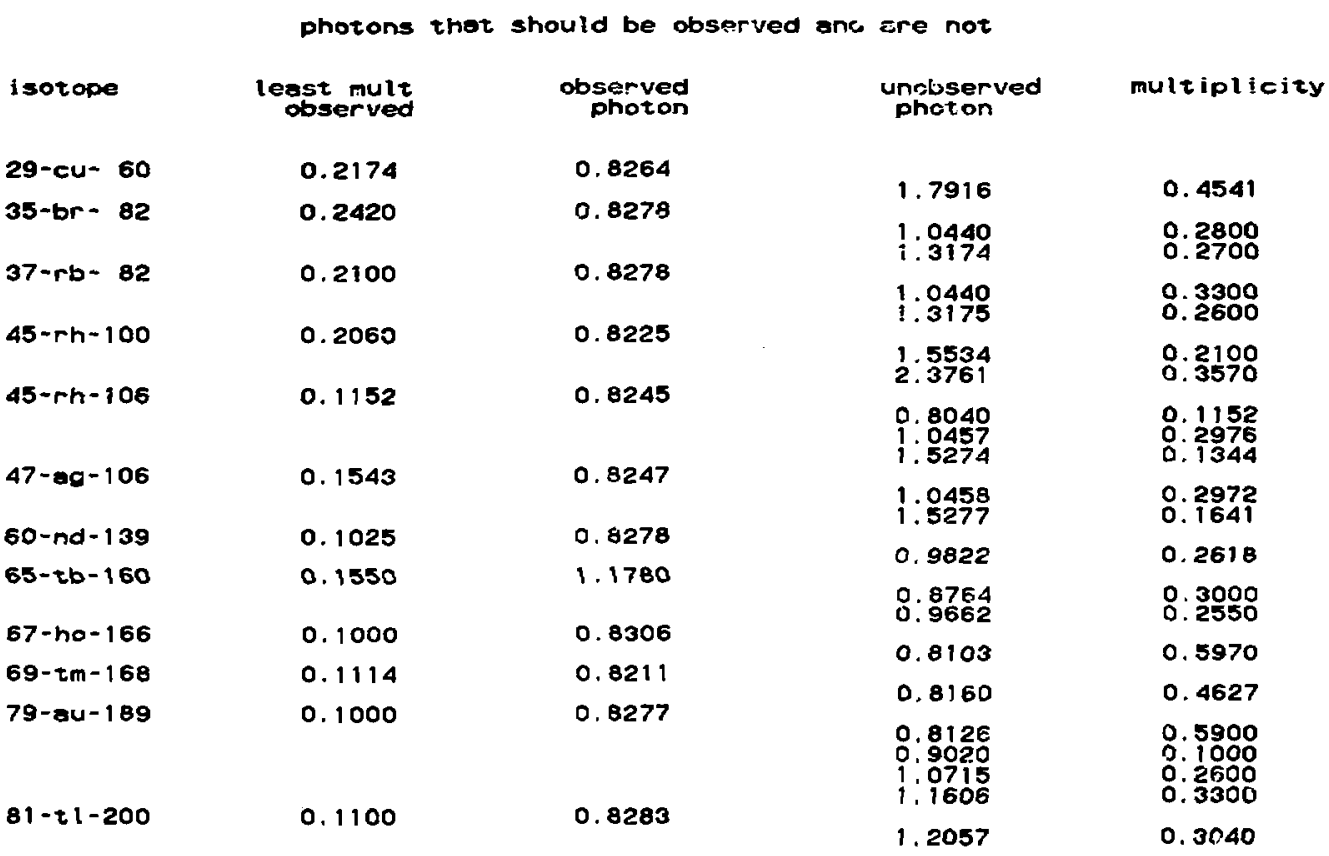

Figure 4. 


\section{Befereaces}

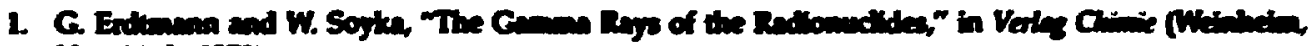
New Boite 15\%?

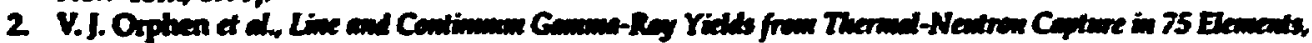

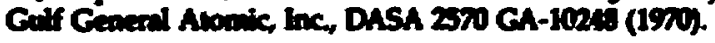




\section{Appendix A. File Structure of GAMTOT78}

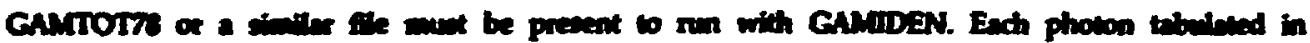

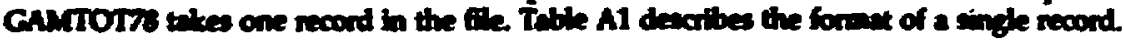

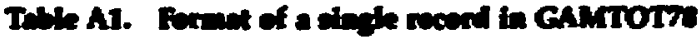

\begin{tabular}{|c|c|c|c|}
\hline syses & Veriable name & Feinen & Decrivitem \\
\hline 1 & IFL & $\mathbf{I I}$ & 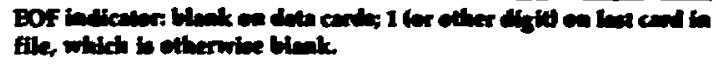 \\
\hline $2-7$ & $\mathbf{L A}$ & IS & 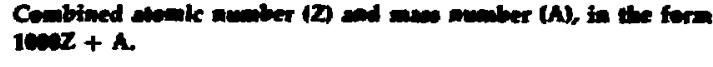 \\
\hline $0-12$ & Elmok & $\mathbf{5 x}$ & \\
\hline 13-19 & GAM & $\mathbf{F 7 . 4}$ & Observed photon energy (in MeV). \\
\hline $20-24$ & Bank & $\mathbf{5 x}$ & \\
\hline 25-33 & $\mathbf{A} \mathbf{l}$ & F9.7 & $\begin{array}{l}\text { Probability (same as multiplicity) of this photon per decay or per } \\
\text { capture. }\end{array}$ \\
\hline 34-38 & Blank & $5 \mathbf{x}$ & \\
\hline $39-48$ & TIME & E10.3 & $\begin{array}{l}\text { Half-life of isotope, numerical value only (unit is next variable), is } \\
\text { equal to } 1.000 \mathrm{E}-14 \text { if this is a prompt (n-capture) photon. }\end{array}$ \\
\hline 49 & Blank & $1 x$ & \\
\hline 50 & IUNIT & $\mathbf{A 1}$ & $\begin{array}{l}\text { Unit is used for half-life: second (S), minute (M), day (D), or year } \\
\text { (Y). }\end{array}$ \\
\hline $51-55$ & Blank & $\mathbf{5 X}$ & \\
\hline $56-59$ & SOURCE & $5 A 8$ & $\begin{array}{l}\text { Source: N,GAM, prompt n-capture; CHA, charged particle-induced } \\
\text { reaction; NTH, thermal or epithermal neutron-induced reaction; } \\
\text { NFA, fast neutron-induced reaction; NFI, thermal neutron- } \\
\text { induced fission of }{ }^{235} \mathrm{U} \text {; NAT, naturally occurring radionuclides; } \\
\text { PHO, photonuclear reaction. }\end{array}$ \\
\hline & & & $\begin{array}{l}\text { Miscellaneous symbols: } A \text {, absolute intensity; } R \text {, relative intensity; } \\
x, x-r a y \text { line; } D \text {, doublet line; } C \text {, complex unresolved lines; } W \text {, weak } \\
\text { intensity; }<, \text { the intensity is less than the value given. }\end{array}$ \\
\hline
\end{tabular}

\footnotetext{
'For all symbols except NFI and NAT the nuclide designator that follows refers to the target nuclide.

${ }^{b}$ For NFI the number following the symbol refers to the cumulative yield of the fission product.

For NAT the number following the symbol is the percentage of natural isotopic abundance.
} 


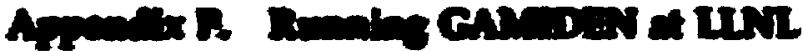

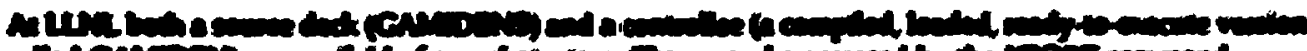

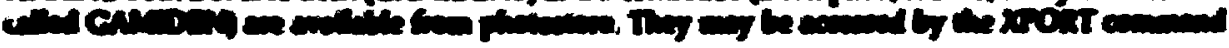

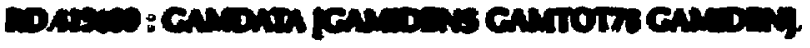

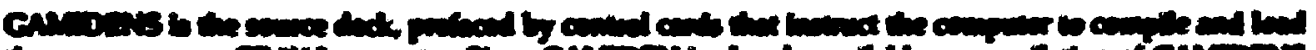

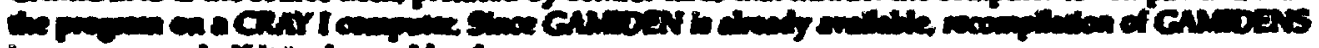

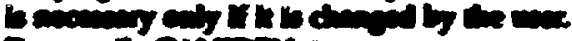

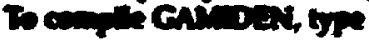

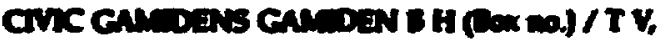

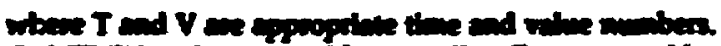

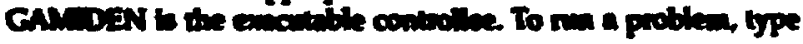

\section{GaMdoen / TV.}

The the and value numbers can be adjubed to the status of the computer. A typicil problem requires less then 0.75 inin.

Plene nole that diak file GaMTOT7s mast be present. 